UCRL 8639

MASTER

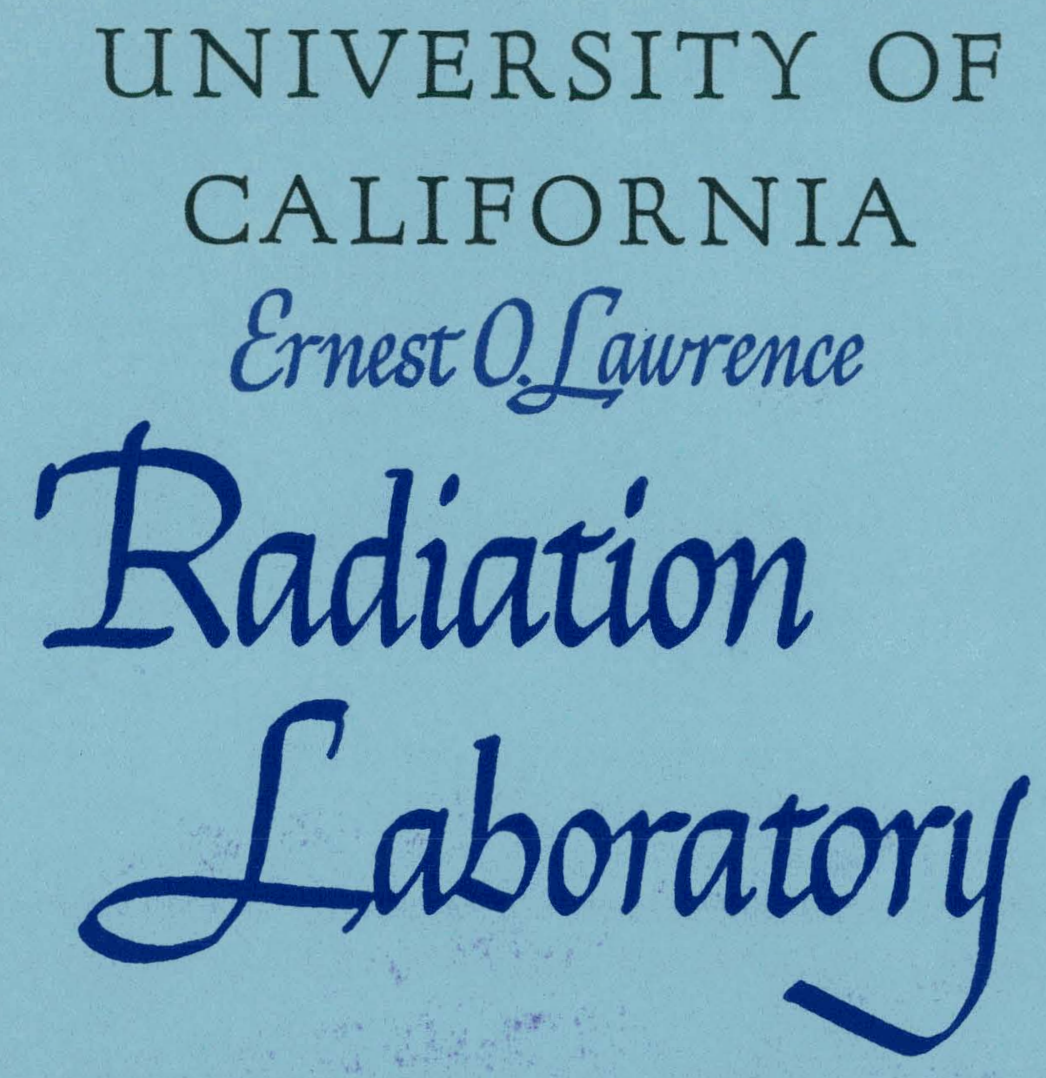

MECHANICAL DESIGN OF A COAXIAL VELOCITY SPECTROMETER FOR HIGH-ENERGY PARTICLES

BERKELEY, CALIFORNIA 


\section{DISCLAIMER}

This report was prepared as an account of work sponsored by an agency of the United States Government. Neither the United States Government nor any agency Thereof, nor any of their employees, makes any warranty, express or implied, or assumes any legal liability or responsibility for the accuracy, completeness, or usefulness of any information, apparatus, product, or process disclosed, or represents that its use would not infringe privately owned rights. Reference herein to any specific commercial product, process, or service by trade name, trademark, manufacturer, or otherwise does not necessarily constitute or imply its endorsement, recommendation, or favoring by the United States Government or any agency thereof. The views and opinions of authors expressed herein do not necessarily state or reflect those of the United States Government or any agency thereof. 


\section{DISCLAIMER}

Portions of this document may be illegible in electronic image products. Images are produced from the best available original document. 
UCRL -8639

Instruments

\author{
UNIVERSITY OF CALIFORNIA \\ Lawrence Radiation Laboratory \\ Berkeley, California \\ Contract No. W-7405-eng-48
}

MECHANICAL DESIGN OF A COAXIAL VELOCITY SPECTROMETER FOR HIGH-ENERGY PARTICLES

Robert A. Kilpatrick

February 1959

\footnotetext{
Printed for the U. S. Atomic Energy Commission
} 


\title{
MECHANICAL DESIGN OF A COAXIAL VELOCITY SPECTROMETER FOR HIGH-ENERGY PARTICLES
}

Robert A. Kilpatrick

Lawrence Radiation Laboratory

University of California

Berkeley, California

February 1959

\begin{abstract}
This report describes the mechanical design of an apparatus in which crossed electrostatic and electromagnetic fields are used to separate highenergy charged particles of different masses. The coaxial geometry of this device allows the separation in about $2 / 3$ the space required with a parallel-plate deflector. The velocity spectrometer described was built specifically to produce enriched beams of $\mathrm{K}^{-}$mesons or antiprotons, but it can be utilized in other applications by changing its parameters. The ratio of particle fluxes in a detector with the spectrometer off and.on is 700 to 1 .
\end{abstract}




\title{
MECHANICAL DESIGN OF A COAXIAL VELOCITY SPECTROMETER FOR HIGH-ENERGY PARTICLES
}

\author{
Robert A. Kilpatrick \\ Lawrence Radiation Laboratory \\ University of California \\ Berkeley, California
}

February 1959

\section{INTRODUCTION}

The idea of using crossed electrostatic $(\mathrm{E})$ and electromagnetic $(\mathrm{H})$ fields to separate high-energy charged particles of different masses was suggested by Joseph Jo Murray, and the general design requirements were worked out by him. This report presents a summary of the mechanical design of the spectrometer; the design calculations are contained in UCID-594.2 Detailed performance data may be found in UCRL-8269。3 Analysis of the transmitted beam by means of an emulsion stack is reported in UCRL-8364。 4

The velocity spectrometer consists of a cylindrical high-voltage shell, and a concentric center conductor at approximately ground potential in which current flows (Fig. 1). A crossed E-H field is produced inside this coax with both $\mathrm{E}$ and $\mathrm{H}$ inversely proportional to radius, so that the ratio $\mathrm{E} / \mathrm{H}$ is constant except for end effects.

The ratio $\mathrm{E} / \mathrm{H}$ is adjusted to match the velocity of the desired particles. The beam to be analyzed is directed along the axis of the spectrometer. The desired particles pass through essentially undeflected, whereas with proper field polarity undesired particles (i.e. those having different velocities) are deflected outward. The present device has been constructed to transmit either $\mathrm{K}^{-}$mesons or antiprotons, but a variation in parameters would allow it to transmit different particles.

A typical experimental arrangement is shown in Fig. 2。 A target located in the acceleration chamber of the Bevatron is flipped azimuthally into the primary (proton) beam, producing a secondary beam which contains the desired particles along with a background of other particles. In the case of $\mathrm{K}^{-}$mesons, the ratio of undesired to desired particles at production is $\sim 1000$ to 1 ; the corresponding figure for antiprotons is $\sim 2 \times 10^{6}$ to 1.3

The secondary beam is then sent through the field of a magnet $(\mathrm{M}-1)$ so that particles with essentially the same momentum enter the velocity spectrometer, which is set to transmit only those of a given velocity. When the beam reaches the detector the number of background tracks per stopped $\mathrm{K}^{-}$meson is 65 to 1 , and for antiprotons 4000 to 1.3 The ratio of particle fluxes in the detector with the spectrometer off and on is 700 to 1.3 


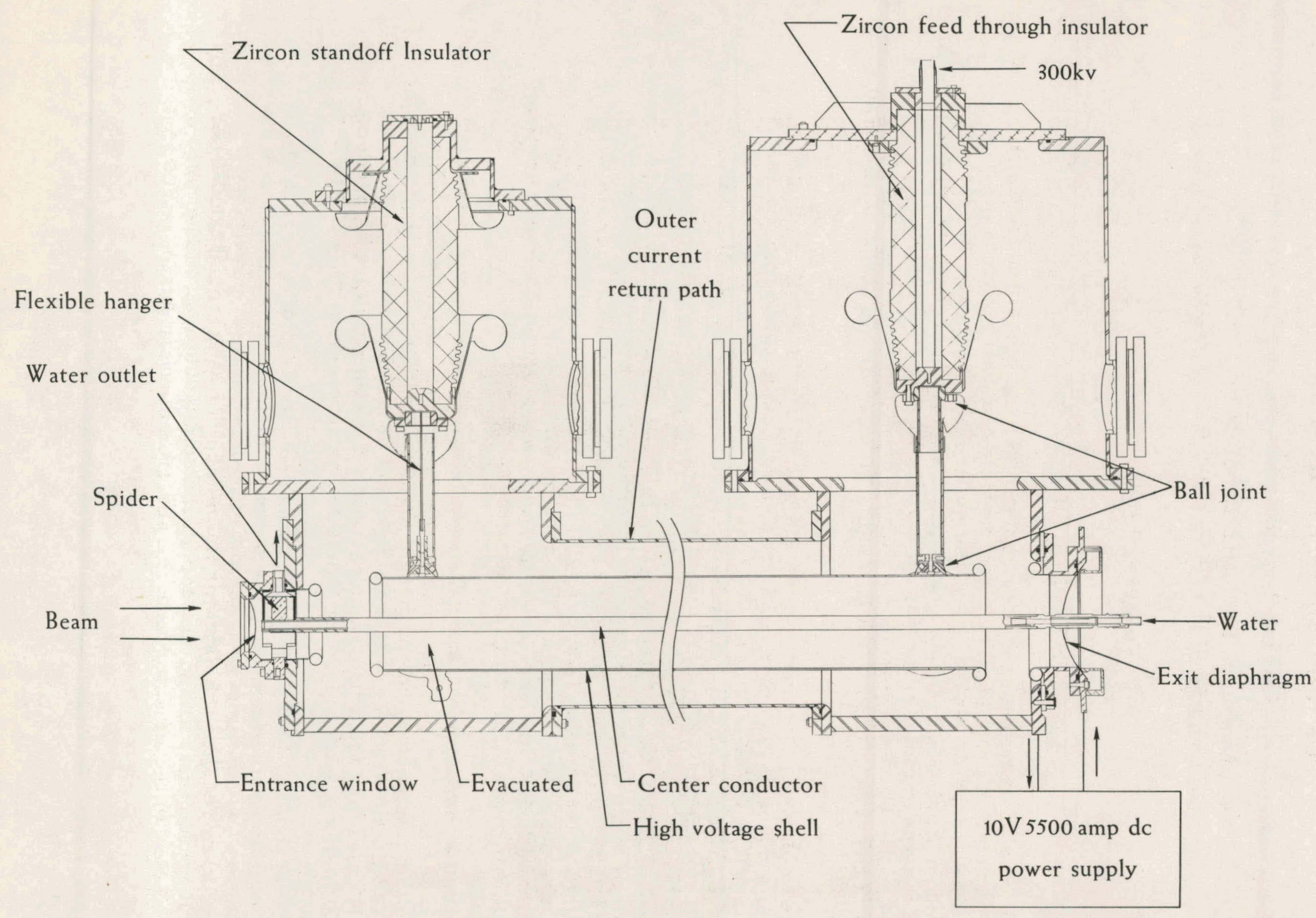




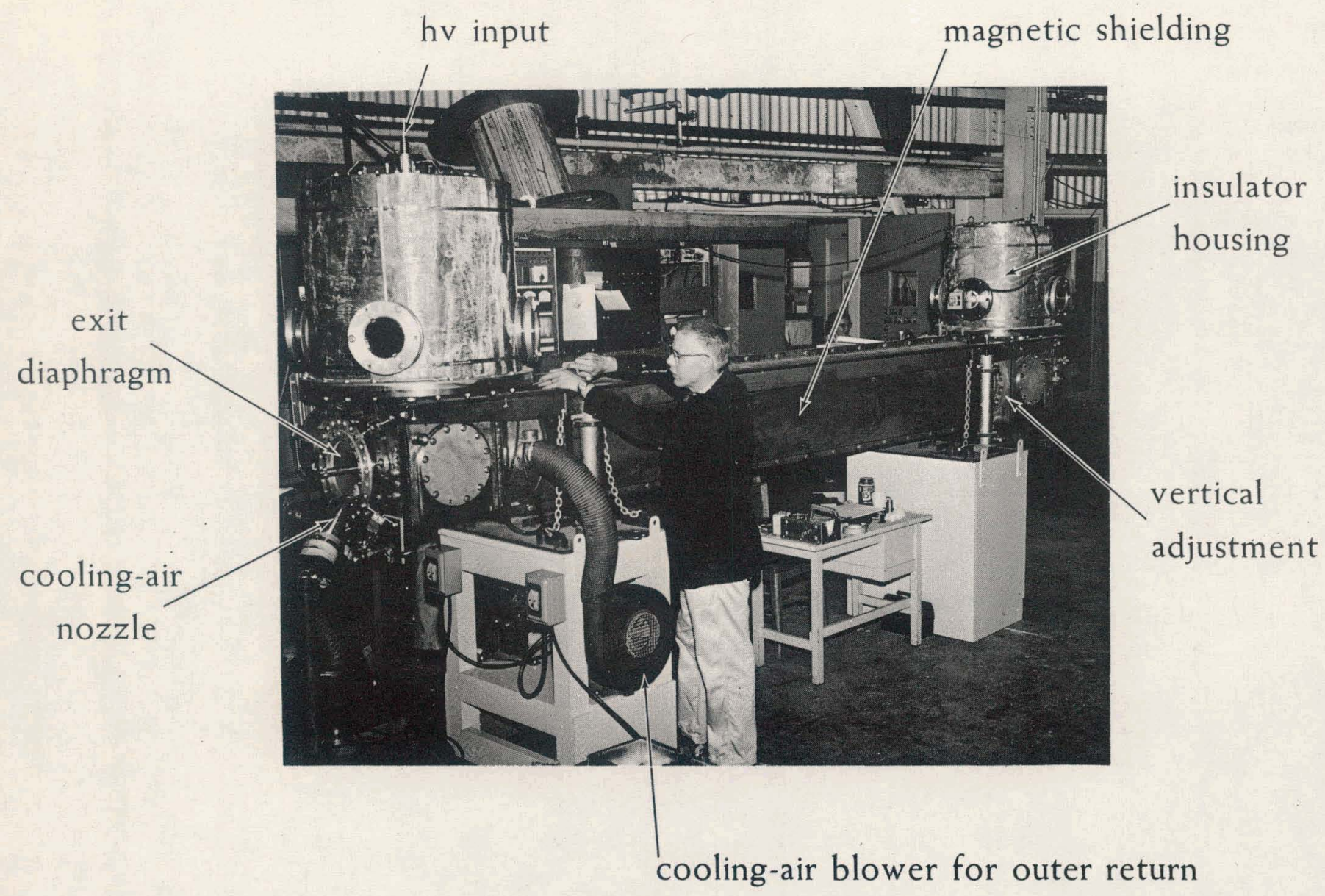

Fig. 1b. Exterior of the spectrometer. 


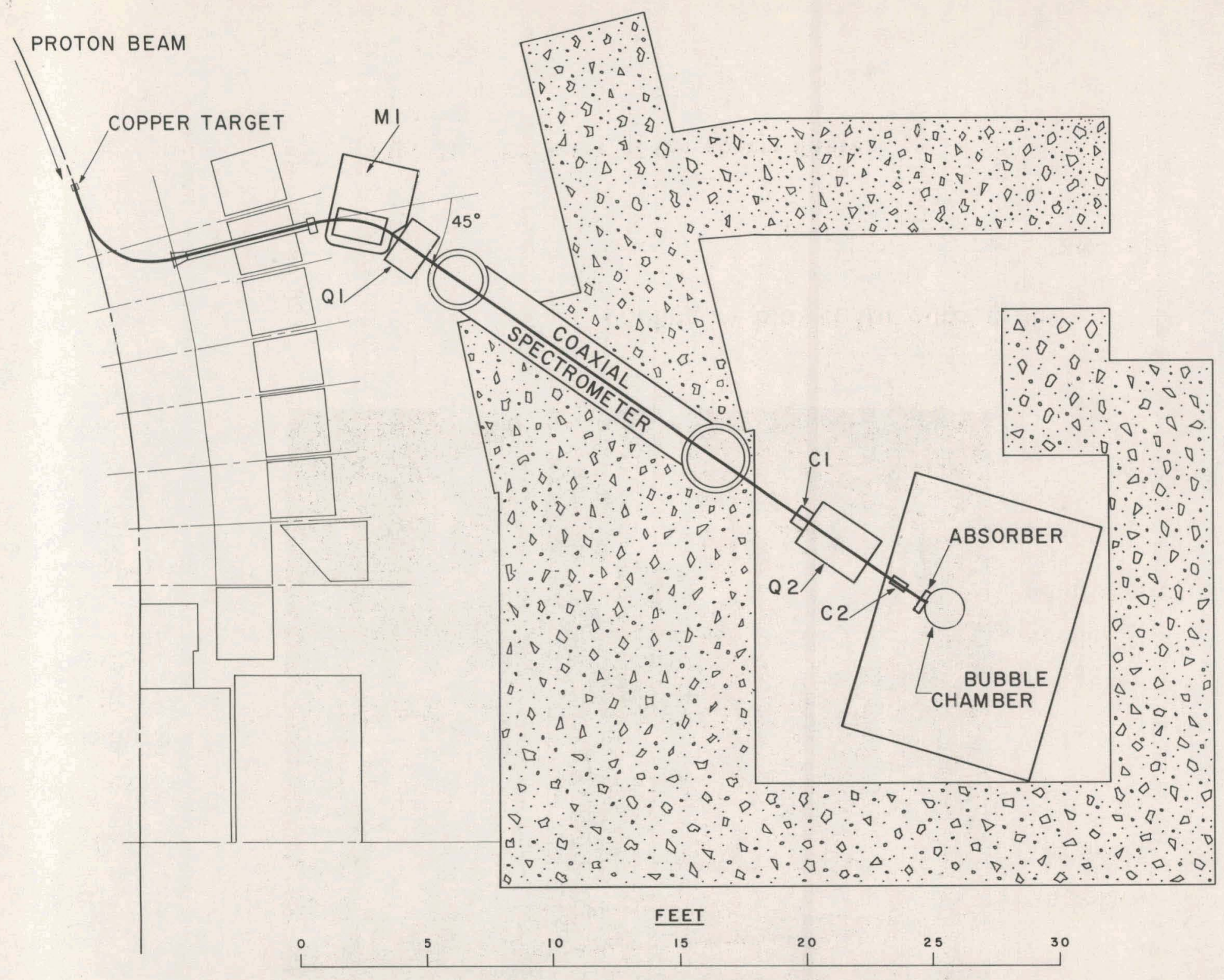


Because of the coaxial geometry, a shorter system is possible than with a parallel-plate deflector. Consequently, a coaxial spectrometer is more efficient in transmitting particles having short lifetimes. The overall transmission efficiency for $\mathrm{K}^{-}$mesons is about $25 \%$ (neglecting decay), and for antiprotons about $15 \%$.

\section{MECHANICAL DESIGN AND CONSTRUCTION}

\section{Center Conductor}

The magnetic field $(\mathrm{H})$ is generated by current flow through the center conductor, and the electrostatic field $(\mathrm{E})$ is established between the center conductor and a concentric high-voltage shell. The center conductor consists of an outer stainless steel tube facing the high voltage (up to $280 \mathrm{kv}$ ), and an inner copper tube which carries the bulk of the high current (4000 amp when the spectrometer is set to transmit $\mathrm{K}^{-}$mesons, and 3000 amp when set for antiprotons). The outside diameter of the stainless steel tube is $1.05 \mathrm{in.}$, and the inside diameter of the copper tube is $0.584 \mathrm{in}$. Cooling water is pumped through the copper tube at approximately $8 \mathrm{gpm}$. The area between the center conductor and the high-voltage shell is evacuated. to $5 \times 10^{-7} \mathrm{~mm} \mathrm{Hg}$ to allow passage of the particle beam with minimum scattering and to provide electrical insulation between the two surfaces.

The center $\infty$ nductor is supported at the entrance end by a 3-spoke copper spider, which conducts the high current and cooling water radially from the center conductor, and yet uses up a practical minimum of the beam aperture. At the exit end of the spectrometer, the center conductor is supported by a thin-metal diaphragm. Because the 14 -ft-long center conductor is supported only at its ends, it was precambered so that it would bend to a straight line when filled with cooling water. The requirement was that it be straight and concentric with the hv shell within. $1 / 16$ in.

' Other considerations in the design of the center conductor were:

a. that it have a proper thermal expansion in order to limit differential expansion between it and the outer return path (vacuum envelope), so that the exit diaphragm will not be damaged;

b. that it be tight to an internal water pressure up to 200 psi and an external vacuum of $5 \times 10^{-7} \mathrm{~mm} \mathrm{Hg}$;

c. that it be stiff enough to withstand shock loads due to normal handling, and deflections due to Bevatron stray fields (pulsed). The natural frequency of lateral vibrations was considered in the design so as to avoid resonance effects. 


\section{High-Voltage Shell}

The high-voltage shell is a cylinder of type-304 stainless steel, $0.090 \mathrm{in}$. thick. The desired inside diameter was 7 in., but fabrication difficulties dictated the use of 6-1/2-in. stock material. Operation of the spectrometer indicates noticeable scattering of the beam from the shell. For this reason, the diameter should be increased to 7 in.

Attempts to hone the inner surface were not altogether successful. A final finish was obtained by sandblasting with dull grit followed by rice hulls. The resulting surface is not ideal, but after initial spark polishing it has been satisfactory.

- The high-voltage shell is suspended from two zircon insulators, one of which is a feed-through for the high voltage and the other a standoff. Between.the high-voltage shell and the insulators are ball-jointed adjustablelength stems to allow positioning the shell concentric with the center conductor to within 1/16 in. One of these stems is flexible in the longitudinal direction in order to avoid stresses due to differential thermal expansion between the hv shell and the outer return path (vacuum envelope).

We plan to reduce the thickness of the hv shell in order to lower its weight and thereby decrease insulator stress.

\section{Outer Current Return (Vacuum Envelope)}

The outer return path for the current flowing through the center conductor is a 12-3/4-in。-diam. stainless steel cylinder 3/16-in。thick。 This cylinder is coaxial with the hv shell and center conductor.

The heating and cooling of this cylinder is balanced with that of the center conductor in order to minimize differential thermal expansion, which would damage the exit diaphragm. This balance is partially achieved by air cooling the cylinder and lowering its resistance with the addition of uniformly spaced copper-wire shunts. During turn-off or turn-on the rate of current change is limited so as to allow the temperatures to equalize. This arrangement is satisfactory during normal operation, but any sudden cut-off of the high current results in damage to the exit diaphragm. Several changes are contemplated for alleviating the problem: The shunt wires are to be replaced with copper straps or sheet, and water cooling is to be installed, with the flow rate controlled by an interlock system in the highcurrent circuit.

In addition to serving as the return path for the high current, this cylinder acts as part of the vacuum envelope for the spectrometer. This envelope is sealed at each end by a thin aluminum window. 


\section{$\underline{\text { Spider }}$}

The spider, which is used at the entrance end to carry the high current and cooling water radially from the center conductor, is shown in Fig. 3 . This design provides the necessary mechanical support for one end of the center conductor, and yet offers the least practical aperture restriction to the beam considering its functions.

The present spider is made of copper; however, in the redesign soon to be undertaken, it will be made of stainless steel in order to avoid the trouble of fastening copper to stainless steel to give absolutely tight joints.

\section{Exit Diaphragm}

The exit diaphragm acts as a vacuum barrier at one end of the spectrometer, serves as an exit window for the beam, and conducts up to $4000 \mathrm{amp}$ dc to the center conductor. It is made of $2 \mathrm{SO}$ aluminum sheet and is hydraulically formed to approximately a 6 -in. spherical radius. The electrical connection and vacuum seal at the center are made by an ungasketed, metal-to-metal joint lightly coated with silicone. vacuum grease just before assembly. A special wrench is used for holding the center conductor while tightening the clamp nut, since twisting the center conductor might damage the spider at the other end.

For operation up to $3000 \mathrm{amp}$, a $15-\mathrm{mil}$ diaphragm is used; for 4000 amp: 20-mil is used.

Aluminum was used in preference to copper or magnesium because. it has the optimum combination of properties from the standpoint of strength, conductivity, and scattering. The diaphragm is fully annealed after forming.

The diaphragm is cooled mainly by forced air flow across it. The air is supplied by an American Blower type $\mathrm{P}$ size $\mathrm{C}$ exhausting through a nozzle approximately 6 in. long having an entrance area 4 in. in diameter and an exit area $3 / 8 \times 6$ in. The nozzle air blast is tangent to the spherical surface of the diaphragm at its perimeter.

\section{Materials}

With the exception of the diaphragms and the spider, all metal facing the high voltage is stainless steel (mostly type 304). Stainless steel was chosen because of its ability to resist sparking, and being nonmagnetic, it does not distort the magnetic field. Surfaces exposed to high gradients were polished to a mirror finish $\left(\mathrm{V}^{2}\right)$ wherever possible in order to help prevent sparkover. 


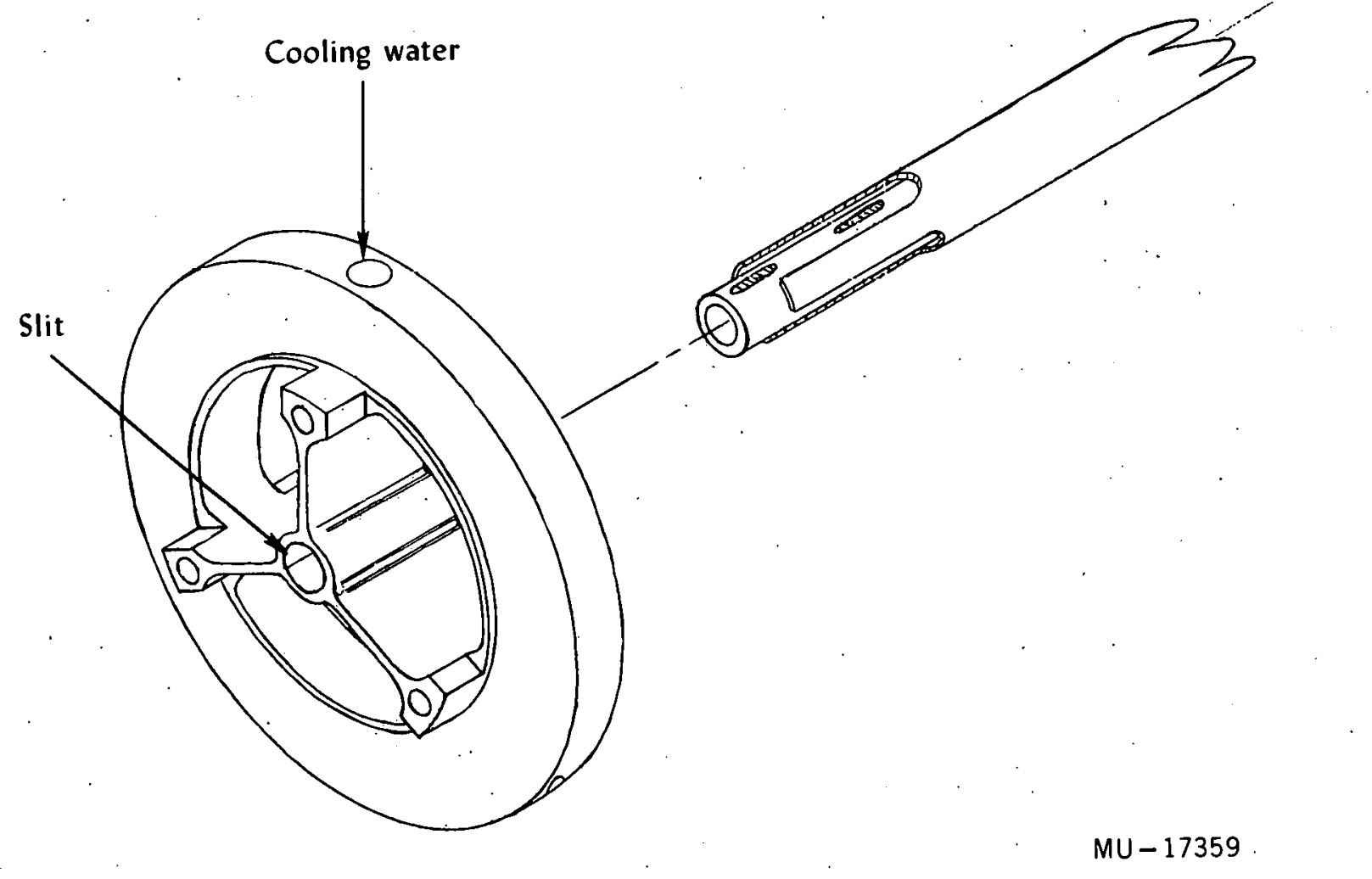

Fig. 3. The spider. 


\section{Entrance Window}

The particle beam enters the spectrometer through a 5-mil 2SO aluminum window, which is hydraulically deformed to a.spherical shape with approximately a 6-in. radius. It is used in the work-hardened temper.

This window also acts as a vacuum barrier at: the entrance end.

\section{Vacuum System}

Throughout the design all practical means were used to avoid virtual leaks so the pump down period.would be short as possible.

Originally, it was thought that vacuum-gasket materials which outgas hydrocarbons would be undesirable, because the ready supply of protons would contribute to sparking. Metal gaskets are not feasible owing to their expense and the difficulties inherent with their use. The recently developed Kel-F elastometer appeared promising, but it is costly and joining techniques had not been developed at the time of construction for making large ring gaskets. It was decided to try standard Hycar gaskets, but to use square grooves instead of the more convenient rectangular grooves, so that Kel-F (which was available only in square extruded sections) could be substituted providing the joining problem was solved.

Hycar has proven satisfactory. The system bases out at about $5 \times 10^{-7} \mathrm{~mm} \mathrm{Hg}$. The spectrometer has been. operated for approximately 1 year at $250 \mathrm{kv}$ with an acceptable spark rate. The new spectrometer will be made with rectangular gasket grooves to accommodate conventional Hycar.

The 6-in. mercury diffusion pump, forepump, liquid-nitrogen trap, reefer, and valves are mounted on a cart. Connection to the spectrometer is made via a large bellows at any of the four corners of the spectrometer assembly. This arrangement facilitates installation at various locations around the Bevatron.

\section{$\underline{\text { De-gaussing Coils }}$}

The first experiment using the spectrometer was set up at the inner radius of the Bevatron west tangent area.. The large stray fields there caused sparking due to ion distribution ("pigging") in the insulator cans, with a resultant voltage breakdown which put the spectrometer out of commission at each Bevatron pulse. Pulsed de-gaussing coils wound around the insulator cans cured this trouble.

At the present location (the $\mathrm{K}^{-}$station) stray fields are reduced and no sparking has been.observed traceable to the fields, so the de-gaussing coils are not used. 


\section{Magnetic Shielding}

A multilayer shield consisting of four concentric mild-steel cylinders, magnetically insulated from each other by brass strips and bolts, surrounds the spectrometer. This shielding reduces the Bevatron.stray. field by a factor of approximately 30. Distortions in the spectrometer magnetic field and magnetic forces on the center conductor are thus minimized.

\section{Mounting}

The magnetic shield is also used as the basis for the supporting structure of the spectrometer body. The support occurs at the ends and is arranged to give only frictional restraint to thermal expansion. Vertical adjustments of $\pm 3 / 4 \mathrm{in}$. at both ends allow vertical aiming of the spectrometer. Jack pads on the base plate facilitate horizontal aiming, which is done. with small "Porto-Power" jacks.

\section{Lead Shielding}

The insulator cans are surrounded with 1/8-in. thick lead sheet in order to shield operating personnel and counting instruments from the high $\mathrm{x}$-ray flux originating inside. This flux has been as high as $200 \mathrm{R} / \mathrm{hr}$. when the high voltage was first applied to the spectrometer, in spite of very careful cleaning techniques. The $x$-ray intensity dropped to safe low values after a period of out-gassing and spark polishing, but the shielding is still required to minimize background in the detectors.

\section{Viewing Ports}

Each insulator can has four viewing ports which are used to observe the insulators for corona or sparks. The ports are plate glass covered with $1 / 8$-in. lead glass for $\mathrm{x}-\mathrm{ray}$ shielding。

\section{Handling}

In spite of much design effort, the spectrometer is a delicate instrument and requires gentle handling when being moved, in order to avoid damage to the center conductor, exit diaphragm, spider, and insulators.

\section{ACKNOW LEDGMENT}

This work was performed under the auspices of the U. S. Atomic Energy Commission。 


\section{REFERENCES}

1. Joseph J. Murray, A Coaxial Static-Electromagnetic Velocity Spectrometer for High-Energy Particles, UCRL-3492, May 7, 1957.

2. R. A. Kilpatrick, Velocity Spectrometer, UCID-594, Feb. 27, 1958.

3. Horwitz, Murray, Ross, and Tripp, 450-Mev/c $\mathrm{K}^{-}$and $\overrightarrow{\mathrm{p}}$ Beams at the Northwest Target Area of the Bevatron Separated by the Coaxial Velocity Spectrometer, UCRL-8269, June 1958.

4. John N. Dyer, Analysis of the Bevatron $\mathrm{K}^{-}$Beam by Means of an Emulsion.Stack, UCRL-8364, July 1958. 
This report was prepared as an account of Government sponsored work. Neither the United States, nor the Commission, nor any person acting on behalf of the Commission:

A. Makes any warranty or representation, expressed or implied, with respect to the accuracy, completeness, or usefulness of the information contained in this report, or that the use of any information, apparatus, method, or process disclosed in this report may not infringe privately owned rights; or

B. Assumes any liabilities with respect to the use of, or for damages resulting from the use of any information, apparatus, method, or process disclosed in this report.

As used in the above, "person acting on behalf of the Commission" includes any employee or contractor of the Commission, or employee of such contractor, to the extent that such employee or contractor of the Commission, or employee of such contractor prepares, disseminates, or provides access to, any information pursuant to his employment or contract with the Commission, or his employment with such contractor. 